\title{
O PROBLEMA DA IMPARCIALIDADE DO JUIZ NO SISTEMA PENAL BRASILEIRO: ANÁLISE COMPARATIVA ENTRE BRASIL E ITÁLIA ${ }^{1}$
}

THE PROBLEM OF THE JUDGE'S IMPARTIALITY IN THE BRAZILIAN CRIMINAL SYSTEM: COMPARATIVE ANALYSIS BETWEEN BRAZIL AND ITALY

Pedro Avalos HALLAK ${ }^{2}$

Clóvis Alberto VOLPE FILHO

ISSUE DOI: 10.21207/2675-0104.2019.921

\begin{abstract}
RESUMO
O presente trabalho inicialmente introduzirá ao leitor a teoria do garantismo penal, cunhada por Ferrajoli com o fundamento de limitar o poder estatal e diminuir os abusos cometidos no exercício da pretensão punitiva. Em um segundo momento, será abordado o tema da investigação preliminar no processo penal, com foco voltado para o modelo adotado no Brasil, qual seja, o inquérito policial e suas peculiaridades. Ao final, o objetivo será concluir sobre a importância ou não de se inserir a investigação criminal defensiva no ordenamento jurídico brasileiro, tendo por base a efetivação dos direitos e
\end{abstract}

\footnotetext{
${ }^{1} \mathrm{O}$ presente artigo sintetiza a monografia de conclusão da pesquisa, realizada para o Programa Interno de Bolsas de Iniciação Científica (PIBIC 2018-2019) da Faculdade de Direito de Franca (FDF), Franca/SP.

${ }^{2}$ Discente da Faculdade de Direito de Franca (FDF), Franca/SP. Bolsista do Programa Interno de Bolsas de Iniciação Científica (PIBIC 2018-2019).

3 Possui graduação em Direito pela Faculdade de Direito de Franca (2003), mestrado em Direito Constitucional pela Universidade de Franca (2005), especialização em Ciências Criminais pela Puc-Minas (2011) e MBA em Direito Empresarial pela FGV (2011). É doutor em Direito Constitucional pela Fadisp, advogado e professor da graduação da Fafram/Ituverava e da Faculdade de Direito de Franca. Tem experiência na área de Direito, com ênfase em Direito Constitucional, Direito Penal e Direito Processual Penal. Foi pesquisador/bolsista durante a graduação pela Fapesp, e durante o mestrado pesquisador/bolsista pela Capes.
} 
garantias individuais assegurados pela Constituição Federal. A metodologia utilizada será majoritariamente qualitativa, através de pesquisas bibliográficas e documentais, especialmente em doutrinas, artigos científicos e monografias de pesquisadores do processo penal.

Palavras-chave: garantismo penal. garantias fundamentais. investigação preliminar. investigação defensiva. processo penal.

\begin{abstract}
The present study will initially introduce the reader to the theory of penal guaranteeism, coined by Ferrajoli on the grounds of limiting state power and reducing abuses committed in the exercise of punitive pretense. In a second moment, the theme of the preliminary investigation in the criminal process will be addressed, focusing on the model adopted in Brazil, namely the police investigation and its peculiarities. In the end, the objective will be to conclude on the importance or not of inserting the defensive criminal investigation in the Brazilian legal system, based on the realization of the individual rights and guarantees ensured by the Federal Constitution. The methodology used will be mostly qualitative, through bibliographic and documentary research, especially in doctrines, scientific articles and monographs of criminal process researchers.
\end{abstract}

Keywords: criminal guaranteeism. fundamental guarantees. preliminary investigation. defensive investigation. criminal proceedings.

A investigação criminal preliminar, também conhecida como instrução preliminar, corresponde à fase inicial da persecução, anterior ao ajuizamento da ação penal propriamente dita, mas intimamente relacionada e extremamente importante para a esfera do processo penal. Nesta etapa, o órgão oficial responsável por esta função deve atuar na colheita de elementos informativos relacionados a uma suposta prática delitiva que chegou ao seu conhecimento, visando apurar o fumus comissi deliciti.

Restando devidamente comprovada a materialidade delitiva e havendo indícios concretos que apontem para a autoria, os autos do inquérito devem ser encaminhados ao titular da ação penal, o Promotor de Justiça membro do Ministério Público, para que ele decida se deve ou não denunciar o investigado. Nota-se, assim, a importância da investigação preliminar, em especial como filtro para evitar acusações indevidas e medidas cautelares desnecessárias, as quais podem trazer prejuízos imensuráveis àqueles sob o qual recaem.

Apesar de seu papel fundamental na solução de crimes, muito ainda se critica sobre este procedimento e suas principais características, em especial o seu caráter inquisitivo. Em razão deste, a maioria das garantias individuais asseguradas pela Constituição Federal acabam marginalizadas nesta fase pré-processual, em especial os princípios do contraditório, da ampla defesa e da igualdade, que são basilares em qualquer Estado Democrático de Direito. Isto acaba colidindo com o 
próprio fundamento da existência do Processo Penal, cuja função principal é a de efetivar tais direitos fundamentais durante toda a persecução penal.

Em tese, o prejuízo não seria tão significante, uma vez que os indícios coletados durante a investigação deveriam servir somente para a formação da opinio deliciti do acusador, não podendo ser utilizados para fundamentar as futuras decisões judiciais do magistrado. $\mathrm{Na}$ prática forense, entretanto, é justo o que acontece: os autos do IP se tornam parte do processo, podendo ser revisitados a qualquer momento e servindo de respaldo para sentenças condenatórias que, não fosse por isso, seriam desprovidas de qualquer fundamento.

Diante desta situação, o presente trabalho visa questionar se não seria importante permitir que o investigado, através de seu defensor, possa realizar sua própria investigação preliminar, visando reunir elementos de descargo que lhe possam beneficiar antes mesmo de lhe ser movida qualquer ação. Com isso, haveria desde logo uma maior igualdade entre os envolvidos nesta fase de instrução, afinal é justo dizer que o modelo investigativo adotado atualmente no Brasil serve exclusivamente para o acusador, tornando uma relação que já é totalmente desequilibrada ainda mais desigual.

\section{A TEORIA DO GARANTISMO PENAL E A INSTRUMENTALIDADE DO PROCESSO PENAL}

Para que se torne possível uma análise acerca da necessidade ou não de se instituir a investigação criminal defensiva no ordenamento jurídico brasileiro sob o prisma do garantismo penal, torna-se imprescindível uma análise acerca desta valorosa teoria. Diante desta necessidade, porém sem qualquer pretensão de esgotar o assunto, mas tão somente introduzindo algumas noções gerais sobre as ideias de Ferrajoli, passa-se agora à exposição do referido tema.

Em uma brevíssima recapitulação histórica, é importante ressaltar que a partir do momento em se passa a proibir a vingança privada por parte da vítima contra aquele que delinquia, o ius puniendi torna-se um direito exclusivo do Estado, que implementa critérios para que se busque a justiça. O mestre Aury Lopes Júnior explica que:

O Estado, como ente jurídico e político, avoca para si o direito (e o dever) de proteger a comunidade e também o próprio réu, como meio de cumprir sua função de procurar o bem comum, que se veria 
afetado pela transgressão da ordem jurídico-penal, por causa de uma conduta delitiva. (LOPES JÚNIOR, 2018, p. 51)

A partir do momento em que estas mudanças começam a ocorrer, surge a necessidade de se limitar todo este poder que agora residia unicamente nas mãos do Estado, a fim de se evitar abusos e injustiças. No entanto, não foi bem isso que aconteceu, e sim, pelo contrário, os monarcas absolutistas se aproveitaram de sua situação para aplicar as leis como bem lhe conviesse. Tal situação perdurou por vários séculos, até que os ideais filosóficos oriundos do iluminismo que se iniciou no século XVIII passaram a surtir efeitos, dando início ao que se tornariam os primeiros direitos fundamentais.

Já muitos anos depois, a teoria denominada de Garantismo Penal foi proposta pelo jurista italiano Luigi Ferrajoli por volta da década de 1970, sofrendo fortes influências do momento histórico da época bem como dos movimentos iluministas e liberais. As recentes guerras que assolaram o continente europeu criaram um contexto propício para que tais ideias se propagassem, afinal urgia-se uma sociedade em que se assegurassem a efetiva proteção dos direitos e garantias fundamentais. (GUIMAR ÃES, 2017, p. 48)

Referidas garantias, em especial aquelas à disposição dos acusados no processo penal, passaram por uma longa e árdua evolução ao longo da história jurídica. De fato, foram alcançadas somente após a constatação de que as violências cometidas pelo Estado neste ramo do Direito seriam as mais injustas ante a clara desigualdade entre defesa e acusação. Neste sentido, o garantismo penal foi concebido a partir do entendimento de que o "Estado de Direito" serviria em primeiro lugar para a proteção do indivíduo, que será sempre o elo mais fraco na relação contra o poder estatal. (COSTA, 2016, p. 169)

Assim, mais uma vez de acordo com Lopes Júnior, os direitos fundamentais:

Dirigem-se contra o Estado, e pertencem, por conseguinte, à seção que trata do amparo do indivíduo contra o Estado. O processo penal constitui um ramo do Direito Público, e, como tal, implica autolimitação do Estado, uma soberania mitigada. [...] Por isso, Ferrajoli fala da ley Del más débil. No momento do crime, a vítima é o débil e, por isso, recebe a tutela penal. Contudo, no processo penal opera-se uma importante modificação: o mais débil passa a ser o acusado, que frente ao poder de acusar do Estado sofre a violência institucionalizada do processo e, posteriormente, da pena. (LOPES JR., 2011, p. 12-14) 
Nota-se, portanto, que a razão de ser do garantismo reside de fato na necessidade de se conter o ius puniendi estatal, o qual seria inerente à relação processual penal levando-se em consideração todo o poderio à disposição dos órgãos acusatórios. Considerando-se que o Direito Penal incessantemente lida com restrições do direito de ir e vir do imputado, possibilitando inevitavelmente a imposição da maior das restrições que o ser humano pode legitimamente sofrer, Ferrajoli defende a necessidade de se instituir um sistema processual acusatório, no qual sejam efetivadas as garantias constitucionais. (COSTA, 2016, p. 170)

Em seu modelo garantista, o célebre jurista italiano propõe, ainda, a atuação de um Direito Penal mínimo, no qual se reduziria os poderes concedidos ao Estado, em favor de maiores liberdades individuais. Seria possível, assim, alcançar um meio termo equilibrado, evadindo-se dos extremos impostos pela tirania estatal (antiliberalismo) e pela total liberdade (abolicionismo penal). (GUIMARÃES, 2017, p. 48)

Em seu modo de ver, Guimarães (2017, p. 52) afirma que, enquanto modelo normativo, "garantismo" e "Estado de Direito" poderiam ser vistos como sinônimos, uma vez que os direitos implementados pelo primeiro jamais coexistiriam com um sistema de governo autoritário. Afirma-se, portanto, que a teoria de Ferrajoli pressupõe uma Constituição Federal vigorosa, capaz de limitar o poder do Estado através de garantias que foram expostas pelo autor na forma de axiomas associados ao delito, ao processo e à pena:

\author{
A1) Nulla poena sine crimine; \\ A2) Nullum crimen sine lege; \\ A3) Nulla lex (poenalis) sine necessitate; \\ A4) Nulla necessitas sine injusria; \\ A5) Nulla injuria sine actione; \\ A6) Nulla actio sine culpa; \\ A7) Nulla culpa sine judicio; \\ A8) Nulla judicium sine accustone; \\ A9) Nulla accusatio sine probatione; \\ A10) Nulla probatio sine defensione; (FERRAJOLI, 2014, p.91)
}

Alguns anos depois, entre 1987 e 1988, a Assembleia Constituinte brasileira se utilizaria destas premissas para redigir a atual Lei Maior em vigor no país, atribuindo-lhe um inequívoco caráter garantista.

A Carta Magma, no entanto, apenas constitui, ou seja, tão somente inseriu tais garantias no ordenamento jurídico brasileiro, não the incumbindo a tarefa de efetivamente aplicar as mesmas. Para tanto, o processo penal serve-se para assegurar o status libertatis (limitações ao 
poder punitivo estatal visando respeitas os direitos individuais) através de um devido processo legal, conduzido por um magistrado imparcial e determinado por lei, assegurando-se o contraditório, a ampla defesa, a isonomia entre as partes, o in dubio pro reo e, principalmente, a presunção de inocência.

Muito mais do que princípios processuais, referidos conceitos constituem direitos individuais estabelecidas por uma Constituição Federal de cunho garantista, o que só foi possível alcançar depois de muitos séculos de lutas e movimentos sociais, parcialmente graças à teoria concebida por Ferrajoli. De tal modo, a real instrumentalidade do processo decorre da necessidade de se efetivar aquilo que a lei maior introduziu ao ordenamento jurídico brasileiro, visando minimizar os males que afligem aqueles que são submetidos ao poder judiciário.

Para Costa e Neto (2016, p. 187):

O processo penal existe não para proteger a vítima ou a sociedade,
de maneira geral, contra a criminalidade, mas sim o acusado,
justamente por ser este o mais débil em sua relação com o Estado.
Desse modo, o processo penal não serve para proteger a maioria,
mas sim para proteger, ainda que contra a maioria, aqueles cidadãos
individualizados que, não obstante suspeitos, não podem ser ditos
culpados sem provas.

O direito penal material não pode apartar-se do processo, pois, se o fizesse, retornar-se-ia ao estado de absolutismo estatal e todos os direitos individuais conquistados desde então teriam sido em vão. Por tanto, é necessário que se busque cada vez mais o denominado sistema acusatório puro de processo penal, como será visto a seguir, de modo que este não apenas sirva como instrumento para a aplicação da pena, mas também para a efetivação dos direitos constitucionais.

\section{A INCOMPATIBILIDADE ENTRE O MODELO DE INVESTIGAÇÃO BRASILEIRO E O GARANTISMO}

Por muito tempo, o processo penal tratou o indiciado como um simples objeto da investigação preliminar, sem se preocupar em revestirlhe com direitos individuais que visassem limitar o jus puniendi estatal. Deste modo, somente lhe restava a opção de esperar o desenrolar das investigações, não podendo se manifestar de qualquer modo e, muitas 
vezes, sendo submetido aos abusos dos órgãos encarregados por tais procedimentos.

Esta situação, em tese, mudaria drasticamente com a promulgação da Constituição Federal de 1988, cujo caráter garantista insere uma pluralidade de garantias fundamentais, em especial na esfera do Direito Penal. O investigado, então, deixaria de ser visto como um mero objeto e se tornaria um verdadeiro sujeito de direitos, ao passo em que os poderes do Estado seriam limitados significativamente.

Este deveria ser o panorama atual do ordenamento jurídico brasileiro: uma Lei Maior que constitui garantias e um processo penal criado para efetivá-los. No entanto, referidas garantias ficaram restritas à fase judicial da persecução penal, enquanto que muito pouco parece ter mudado na fase preliminar, afinal, como já discutido, no inquérito policial não incide o contraditório, a ampla defesa ou a igualdade.

Esta limitação até faz algum sentido em determinados casos, pois certas diligências dependem do sigilo para serem bem sucedidas. Contudo, diante destas circunstâncias, tais provas inevitavelmente acabam produzidas unilateralmente, sem o crivo do contraditório e sem a possibilidade de defesa ou renovação, o que fere todo o sistema de garantias. Ademais, são raros os casos em que o sigilo absoluto é realmente imprescindível, sendo que na maioria deles a participação do indiciado para se defender não interferiria negativamente o andamento da investigação.

É inegável que o indiciado é o principal interessado no deslinde da investigação preliminar. Em um primeiro momento seu principal objetivo deve ser evitar acusações infundadas e a adoção medidas cautelares privativas de liberdade ou restritivas de direito, que acabam adquirindo um caráter de pena antecipada. No entanto, seu interesse vai mais além do que eventuais medidas que podem lhe ser impostas, incidindo também na fase judicial, afinal muitas das provas que fundamentarão uma condenação futura são obtidas ainda no IP, sem que ele possa tomar qualquer atitude. (NUCCI, 2016, p. 41)

Neste ponto que surge a principal incompatibilidade entre o modelo de investigação utilizado no ordenamento jurídico brasileiro e a teoria do garantismo penal proposta por Ferrajoli, com todos os seus desdobramentos. Afinal, os indícios colhidos durante a investigação deveriam servir tão somente para a formação da opinio deliciti do titular da ação penal, o Promotor de Justiça, não podendo influenciar o julgamento final pelo Juiz de Direito, razão pela qual muitos defendem que os autos do inquérito sequer deveriam constar no processo. (MACHADO, 2009, p. 87) 
O próprio Código de Processo Penal, cuja função precípua seria a de efetivar as garantias individuais, acaba limitando-as na fase investigativa. Com efeito, o próprio art. 155 do referido diploma legal possibilita que o magistrado se utilize dos indícios colhidos na investigação, portanto sem a incidência do contraditório, para fundamentar suas decisões, desde que o faça em combinação com outros elementos probatórios.

Nucci( 2016, p. 41), citando a lição de Antônio Scarance Fernandes, explica que esta prática forense, cada vez mais comum nos fóruns e tribunais espalhados por todo o país, representa uma clara "ofensa aos princípios do contraditório, da ampla defesa e da presunção de inocência". A seu ver, o inquérito policial estaria assumindo uma "função anômala, não condizente com os citados princípios", de modo que este modelo de investigação não está de acordo com a noção de processo penal acusatório que se espera em um Estado Democrático de Direito.

$\mathrm{O}$ autor prossegue, argumentando que:

\begin{abstract}
Defender o contrário, classificando o nosso sistema como acusatório puro, é omitir que o juiz brasileiro produz prova de ofício, decreta a prisão do acusado de ofício, sem que nenhuma das partes tenha solicitado, bem como se vale, sem a menor preocupação, de elementos produzidos longe do contraditório, para formar sua convicção. Fosse o inquérito, como teoricamente se afirma, destinado unicamente para o órgão acusatório, visando à formação da sua opinio delicti e não haveria de ser parte integrante dos autos do processo, permitindo-se ao magistrado que possa valer-se dele para a condenação de alguém.
\end{abstract}

Ademais, com a edição de Lei n. ${ }^{\circ}$ 11.690/08, o art. 156 do Código de Processo Penal facultou ao julgador "ordenar, mesmo antes de iniciada a ação penal, a produção antecipada de provas consideradas urgentes e relevantes" bem como "determinar, no curso da instrução ou antes de proferir sentença, a realização de diligências para dirimir dúvida sobre ponto relevante". Ambas as hipóteses reforçam ainda mais o poder instrutório do magistrado, o qual, infelizmente, quase que inevitavelmente acaba sendo utilizado somente para confirmar um pré-julgamento condenatório.

Por fim, sistemas em que a instrução preliminar é função exclusiva de órgãos oficiais do Estado, como no caso das policias civil e federal, os elementos coletados nesta fase serão sempre destinados ao acusador, e nunca ao acusado. De tal sorte, a investigação se torna, como colocou Aury Lopes Júnior (2014, p. 97), “uma via de mão única” que 
busca "a todo custo municiar o titular da ação penal". Assim, muito pouco do que é produzido na primeira metade da persecução penal serve ao indiciado, que só poderá exercer de fato seu direito à prova durante fase processual, algo totalmente incompatível com um sistema de garantias.

\section{O DIREITO À PROVA E A INVESTIGAÇÃO CRIMINAL DEFENSIVA}

No processo penal, prova é tudo aquilo que pode ser utilizado legalmente com a finalidade de influir na convicção do julgador acerca da um fato ou alegação. O direito à prova é assegurado tanto para a acusação como para a defesa e deriva das garantias do contraditório, da ampla defesa e da igualdade, possibilitando que as partes demonstrem a veracidade de suas teses seja coletando documentos e informações ou manifestando sempre que thes convir. (MACHADO, 2009, p. 89)

$\mathrm{O}$ direito à prova para a defesa está consagrado em diversos dispositivos do Código de Processo Penal. O art. 155 do referido diploma, por exemplo, determina que "a prova da alegação incumbirá a quem a fizer". Ora, se a lei exige que a defesa prove suas alegações, por certo ela também lhe garante o direito de produzir tais provas. Os arts. 396-A e 400 da lei processual, por sua vez, garantem ao acusado a iniciativa probatória, enquanto que $\mathrm{o}$ art. 402 possibilita que ele requeira diligências.

Fica claro, portanto, que, ao menos durante o processo, o denunciado, assim como a acusação, tem o direito à prova $\mathrm{e}$ a iniciativa probatória assegurados por lei, enquanto que o juiz atua somente de forma subsidiária. Mas se isto ocorre na fase judicial da persecução penal, porque não deveria ser o mesmo na fase de investigação preliminar? Por mais que nesta etapa a cognição seja sumária e os danos não sejam tão devastadores quanto os de uma condenação, ainda assim envolve uma série de liberdades fundamentais do indivíduo e pode lhe causar danos irreparáveis, como a adoção de medidas cautelares privativas de liberdade.

Na prática, o que ocorre no inquérito policial é uma inversão dos princípios acusatórios, porquanto a lei garante mais poderes ao julgador do que ao indiciado para opinar no rumo das investigações ou requerer diligências. E mais, neste sistema, o poder de investigar fica retido exclusivamente sob o controle de órgãos estatais oficiais (em especial as policias civis e federais e o Ministério Público), o que contribui ainda mais 
para o fortalecimento dos elementos acusatórios e consequente redução da possibilidade de defesa.

Ao realizar um estudo comparado entre a realidade brasileira e a de alguns países europeus, Aury Lopes Jr. chegou à conclusão de que:

Como forma de minorar essa grave realidade, sistemas como o italiano (art. 358) e o alemão ( 160 da StPO), preveem a obrigação de que o Ministério Público (titular da investigação) também diligencie sobre fatos e circunstâncias que possam ser favoráveis ao imputado. Em específico, no italiano, existe a possibilidade art. 327-bis - de outorgar atividade investigatória ao próprio defensor, a fim de integrar os autos da indagine, bem como garantir que determinado meio de prova não se escoe, prejudicando, assim, a função defensiva, que sofrerá os efeitos da perda do material probatório já na fase jurisdicional. (LOPES JÚNIOR, 2014, p. 98)

É importante que o direito à prova seja reconhecido também fora do processo, através da expansão do direito à investigação. Se existe um órgão oficial do Estado altamente equipado e destinado a colheita de provas para respaldar uma acusação, a isonomia exige que o acusado também possa agir ativamente para refutar os indicio que apontam para a materialidade e autoria delitiva, evitando o seguimento da persecução penal.

A Constituição Federal brasileira se propôs a adotar um sistema processual garantista acusatório, isto é inegável. No entanto, os direitos fundamentais que ela garante parecem ficar restritos ao plano da ação penal, olvidando-se que existe uma fase anterior com a mesma importância. Justamente neste momento que se espera uma participação muito mais ativa do acusado e seu defensor com o intuito de coletar indícios que suportem suas teses de defesa.

Em outras palavras, é preciso que as garantias constitucionais, em especial o contraditório, a ampla defesa e a igualdade, incidam em toda a persecução penal, mesmo na investigação. Machado (2009, p. 93-94) explica:

De fato, consoante o princípio da isonomia, as partes devem ter paridades de armas, ou seja, os mesmos direitos, ônus e deveres, em cada grau e estado do procedimento. Assim, se, de um lado, existe a investigação pública cujo objetivo precípuo é reunir material probatório para amparar a opinio deliciti do Ministério Público ou da acusação privada; de outro, deve-se permitir que o imputado, por meio de seu defensor, efetua atividade investigatória para suportar suas teses de defesa. 
$\mathrm{O}$ art. 14 do CPP já permite que $\mathrm{o}$ acusado requisite diligências à autoridade policial, o que demonstra, ainda que minimamente, a incidência do direito à prova em sede de inquérito policial. No entanto, ainda é muito pouco, vez que a autoridade policial pode simplesmente se recusar a realiza-la, caso não a considere pertinente ou relevante para o deslinde do inquérito.

Sendo assim, em um sistema processual de partes, para que se alcance a verdadeira finalidade das garantias fundamentais e, consequentemente, possibilite-se um justo e devido processo penal, é importante que o imputado tenha algum modo de se defender ainda durante as investigações preliminares. Portanto, considerando o caráter inquisitório do inquérito policial, bem como sua forte tendência a servir exclusivamente à acusação, deve-se permitir que a defesa conduza sua investigação autônoma, que busque tão somente elementos de descargo capazes de demonstrar a inocência do indiciado antes mesmo do início do processo penal.

\section{CONSIDERAÇÕES FINAIS}

A teoria do garantismo penal de Ferrajoli, apesar de concebida algumas décadas atrás, em um momento histórico totalmente diferente do que se presencia hoje em dia, continua extremamente relevante nos tempos modernos. Nos últimos anos, a sociedade atual parece ter adotado uma postura extremamente punitivista, vendo no direito penal a solução para todas as mazelas que se espalharam pelo país.

Com isso, cria-se um número cada vez maior de medidas punitivas e encarceradoras, e estas, por sua vez, cada vez mais severas, ao passo em que os direitos humanos e individuais são totalmente desprezados pela maior parcela da população. É preciso mudar este cenário com urgência, sendo a função essencial do processo penal a efetivação das garantias fundamentais previstas na Constituição Federal de 1988, assim como a limitação do jus puniendi do Estado.

A investigação criminal preliminar, por sua vez, trata-se de um procedimento preliminar e preparatório para a segunda fase da persecução penal, a ação propriamente dita, cujo objetivo principal é reunir elementos esclarecedores acerca de uma suposta infração penal contida na notitia criminis. No entanto, possui ainda uma segunda função de extrema importância: inibir o ajuizamento de processos penais infundados, ou seja, 
contra pessoas inocentes, protegendo as liberdades individuais destas, além de evitar gastos desnecessários para o poder público.

No Brasil, o modelo de investigação criminal adotado é majoritariamente o inquérito policial, presidido sempre pelo Delegado de Polícia, que poderá, discricionariamente, lhe dar o rumo que entender ser o melhor. A polícia judiciária não está vinculada nem é subordinada ao Ministério Público, de modo que o Promotor de Justiça exercerá somente o papel de fiscalização da atividade policial, mas podendo requisitar as diligências que julgar serem necessárias para a elucidação dos fatos.

Apesar de que apenas ao final do procedimento investigativo o órgão ministerial receberá os autos do inquérito para que possa ajuizar a ação penal, desde esta fase prévia ele acaba assumindo uma postura de acusador, visando comprovar a materialidade e autoria delitiva. Deste modo, a instrução preliminar se torna um instrumento a favor da acusação, de caráter inquisitivo e sem as garantias do contraditório, ampla defesa e igualdade para o indiciado.

Esta situação, contudo, não deveria ocorrer nos dias atuais, posto que o imputado há muito tempo deixou de ser visto como um mero objeto da investigação, devendo ser tratado como um sujeito de direitos que possa desfrutar de todos os direitos e garantias estabelecidos na Constituição. E mais, vale ressaltar, desde a promulgação desta, em 1988, o processo penal brasileiro deveria ter adotado o modelo acusatório, o que ocorreu apenas com relação à segunda fase da persecução.

Ainda assim, em teoria, isto não seria o maior dos problemas, afinal, além de essa característica garantir um procedimento muito mais célere, esperar-se-ia que os elementos de informação colhidos durante a fase investigativa serviriam apenas para a formação da opinio deliciti do Promotor de Justiça, ou seja, para que ele decidisse se deveria ou não prosseguir com a persecução através do ajuizamento do processo. Na prática, entretanto, a situação é bem mais problemática, afinal o próprio Código de Processo permite que o juiz se utilize destes indícios para fundamentar suas decisões, desde que não o faça exclusivamente através deles.

O que acontece, portanto, é que muitas condenações penais acabam respaldadas quase que exclusivamente por informações e documentos contidos nos autos do inquérito, os quais foram produzidos sem a observância das garantias fundamentais e de forma unilateral por órgãos estatais que visam municiar a acusação. O imputado, por sua vez, não dispõe de qualquer procedimento que lhe permita tomar uma postura 
mais ativa ainda durante a instrução preliminar, visando afastar o fumus comissi deliciti.

Não se pode negar, entretanto, que já na fase investigatória ocorre uma imputação em face do indiciado, surgindo-lhe o direito de defesa, em especial para evitar medidas cautelares que lhe privem a liberdade ou restrinjam seus direitos, bem como o ajuizamento do processo penal indevido. Havendo direito de defesa, deve incidir também o direito à prova, pois este deriva daquele, permitindo que o investigado reúna elementos probatórios que demonstrem a veracidade de suas alegações, desbancando os indícios acusatórios.

Diante desta situação, passa-se a indagar acerca da possibilidade de se inserir no ordenamento jurídico brasileiro a chamada investigação criminal defensiva. Esta nada mais é do que uma investigação preliminar quase como qualquer outra, ou seja, que busca elucidar os fatos ocultos sobre uma possível prática delitiva, porém com a grande diferença de ser conduzida pela defesa do suspeito de ter cometido o crime, e não pela autoridade policial.

Assim, o defensor, que atualmente apenas pode participar dos atos do inquérito policial, porém limitado ao rumo discricionariamente escolhido pelo Delegado, passaria a presidir a sua própria investigação, com as estratégias que entender serem mais favoráveis para seu cliente e sem qualquer tipo de subordinação à polícia judiciária ou ao Ministério Público.

Este procedimento, além de auxiliar na efetivação das garantias constitucionais, em especial da igualdade e da ampla defesa, seria de extrema importância para equilibrar os poderes da acusação e da defesa na persecução penal. É preciso garantir às partes os mesmos direitos e deveres, pois é disso que se trata a isonomia, e não continuar a ver o acusado como um simples objeto da investigação policial, na qual praticamente e não pode intervir.

É certo que, assim como ocorre com toda grande transformação, a criação deste novo procedimento demandaria aprofundados estudos e reflexões nos campos das ciências criminais. Seria necessária, em primeiro lugar, uma legislação eficaz, capaz de assegurar os direitos e deveres do defensor investigador, os limites de sua atuação visando respeitar as garantias individuais de terceiros, a valoração das provas obtidas desta maneira e uma série de outras questões que poderiam surgir.

No entanto, apesar de todo o trabalho e investimento que esta regulamentação despenderia, o resultado final, se bem feito, poderia vir a 
ser extremamente positivo. Através desta inovação, seria possível respeitar os princípios do contraditório, da ampla defesa e, em especial, da igualdade entre as partes ainda na fase de instrução preliminar, o que se esperaria em um Estado Democrático de Direito em respeito ao processo penal acusatório.

\section{REFERÊNCIAS BIBLIOGRÁFICAS}

ALEXY, Robert. Teoria dos direitos fundamentais. Tradução por Virgílio Afonso da Silva. São Paulo: Malheiros, 2008.

CAPEZ, Fernando. Curso de processo penal. 23. ed. São Paulo: Saraiva, 2016.

COSTA, Oswaldo Poll; VERAS NETO, Francisco Quintanilha. Garantismo à brasileira: uma análise crítica à luz da aplicação do princípio da significância. Revista da Faculdade de Direito - UFPR, Curitiba, v. 61, n. 3, p. 165-187, set./dez. 2016.

FERRAJOLI, Luigi. Direito e razão: teoria do garantismo penal. 4. ed. São Paulo: Revista dos Tribunais, 2014.

GUIMARÃES, Cláudio Alberto Gabriel; MENEZES, Gabriella Mendes. O garantismo penal integral no processo penal brasileiro. Revista Ceuma Perspectivas, São Luís, v. 29, n. 1, p. 48-60, jan./jul. 2017.

LIMA, Renato Brasileiro de. Manual de processo penal: volume único. 4. ed. Salvador: JusPodivm, 2016.

LOPES JR., Aury. Direito processual penal. 14. ed. São Paulo: Saraiva, 2017.

2011.

Direito processo penal e sua conformidade constitucional. Rio de Janeiro: Lumen Juris,

Fundamentos do processo penal: introdução crítica. 4. ed. São Paulo: Saraiva, 2018.

LOPES JR., Aury; GLOECKNER, Ricardo Jacobsen. Investigação preliminar no processo penal. 6 . ed. São Paulo: Saraiva, 2014.

MACHADO, André Augusto Mendes. A investigação criminal defensiva. Orientador: Antônio Scarance Fernandes. 2009. 212 f. Dissertação (Mestrado) - Faculdade de Direito da Universidade de São Paulo, São Paulo, 2009.

MANZANO, Luís Fernando de Moraes. Curso de processo penal. 3. ed. São Paulo: Atlas, 2013.

MARCÃO, Renato. Curso de processo penal. São Paulo: Saraiva, 2014. 
NUCCI, Guilherme de Souza. Código de processo penal comentado. 13. ed. Rio de Janeiro: Forense, 2014.

Manual de processo penal e execução penal. 13. ed. Rio de Janeiro: Forense, 2016.

PACELLI, Eugênio. Curso de processo penal. 20. ed. São Paulo: Atlas, 2016.

RANGEL, Paulo. Direito processual penal. 23. ed. São Paulo: Atlas, 2015. 